\title{
AN EXPERIMENTAL INVESTIGATION ON MECHANICAL BEHAVIOUR OF SiCp REINFORCED Al 6061 MMC USING SQUEEZE CASTING PROCESS
}

\author{
L. NATRAYAN ${ }^{1}$, MAHARSHI SINGH ${ }^{2} \&$ M. SENTHIL KUMAR ${ }^{3}$ \\ ${ }^{1,3}$ School of Mechanical and Building Sciences, VIT University, Chennai, Tamil Nadu, India \\ ${ }^{2}$ Department of Mechanical Engineering, Amity University, Uttar Pradesh, India
}

\begin{abstract}
Currently, Aluminium (Al) 6061 material is used in Automobile and industry applications, Al 6061 matrix material gives good formability with excellent mechanical properties. Reinforcement of distribution is a major problem in some casting methods and to overcome this casting problem, squeeze casting technique was used in this research work, where Aluminium 6061 act as a matrix material and SiCp was used with different volume percentage. The effects of volume in ractions of reinforcements on the composite properties were investigated. The micro structural characterization results revealed a homogenous distribution of $\mathrm{SiC}$ particles in the matrix, which is almost free of pores can be obtained by squeeze casting method. The mechanical characterization revealed that the density, hardness and impact energy of composites increased while increasing the percent volume fractions of SiC particles.
\end{abstract}

KEYWORDS: Aluminium 6061, SiC, Squeeze Casting Technique, MMC, Volume Fraction \& Mechanical Characterization

Received: Nov 02, 2017; Accepted: Nov 23, 2017; Published: Dec 18, 2017; Paper Id.: IJMPERDDEC201774

\section{INTRODUCTION}

In recent years, aluminum alloys are replaced by aluminium matrix composites in the automobile industry to improve the energy efficiency and environmental requirements [1]. Aluminium matrix composites are known for their excellent physical and mechanical properties. The soft aluminium is reinforced with hard and stiff ceramic particles. The structural aluminium alloys, such as $6 \mathrm{xxx}$ and $7 \mathrm{xxx}$ series are the most commonly used matrix materials due to their low density and high thermal conductivity [2]. In literature survey, some authors investigated and reported unreinforced alloys that gives less mechanical properties, compared to particulate reinforced composites.

The inexpensive ceramic reinforcements such as $\mathrm{SiC}, \mathrm{Al}_{2} \mathrm{O}_{3}$ particles are the most widely used reinforcements in metal matrix composites [3]. Metal matrix composites are generally produced earthier liquid metallurgy or powder metallurgy techniques $[4,10]$. In the casting techniques, particulate segments were mechanically distributed in the liquefied earlier for solidification of the melt. Hence, the squeeze casting method is known as a very promising route for manufacturing near net shape MMC components at relatively lesser cost [4]. The implementation of high pressure during squeeze casting process yield, relatively homogenous and fine microstructure, and improve the adhesion between the molten metal and reinforcement [5-7]. In different environmental temperature condition impact, the behavior of composite was affected by fragile medium reinforcement bonding, clustering of particles and then by cracking [8]. Properties of element clustering on the SiCp reinforced Al Metal matrix composites; the result exposed microstructure and has familiarity, with more percentage of particle fracture, than random distribution and during the tensile deformation, the particle clustering 
has higher effect on the mechanical properties of MMC [9]. We investigated the fracture behaviour and cycle fatigue of $\mathrm{Al}$ 7034/SiCp-UA (Unger-aged) and A17034/SiCp-PA (Peak-aged) MMCs and increase the temperature of two composites, in its ductility and modulus strength of the composite microstructure that has decreased. The deprivation in cyclic fatigue life was more obvious, for the under-aged, than the peak-aged microstructure [10].

\section{MATERIALS AND METHODS}

In this research work, Aluminum 6061 alloy selected as matrix material with the density (theoretical) of 2.7 $\mathrm{g} / \mathrm{cm}^{3}$ and SiCp has been selected as a reinforcement material, with average particle size of $10 \mu \mathrm{m}$. Due to the decrease in the reinforcement, the particle size, higher tensile strength and better ductility was achieved in previous research report [11]. Squeeze casting process were used to fabricate the Al 6061 and SiCp metal matrix composite. Table 1 and 2 shows that, chemical composition of Al6061 alloy and SiCp. The volume fractions of SiCp reinforcement are 10\%, $15 \%$ and $20 \%$.

Table 1: Chemical Composition of Aluminium 6061alloy

\begin{tabular}{|l|c|c|c|c|c|c|c|c|c|}
\hline Elements & $\mathbf{M n}$ & $\mathbf{C r}$ & $\mathbf{F e}$ & $\mathbf{C u}$ & $\mathbf{S i}$ & $\mathbf{M g}$ & $\mathbf{Z n}$ & $\mathbf{T i}$ & $\mathbf{A l}$ \\
\hline (Wt. \%) & 0.01 & 0.05 & 0.17 & 0.33 & 0.71 & 1.12 & 0.1 & 0.01 & Balance \\
\hline
\end{tabular}

Table 2: Chemical Composition of SiC Particle

\begin{tabular}{|l|c|c|c|c|c|c|}
\hline Elements & $\mathbf{S i C}$ & $\mathbf{A l 2 O 3}$ & $\mathbf{S i O 2}$ & $\mathbf{F e 2 O 3}$ & FreeC & Others \\
\hline (Wt.\%) & 98.54 & 0.20 & 0.68 & 0.24 & 0.26 & 0.08 \\
\hline
\end{tabular}

In various researches, it was investigated that, the reinforcement preheating to eliminate the desorbing gases, surface impurities and amend surface composition. Most of the authors reported that, Preheating temperature of the reinforcement range is $200-800^{\circ} \mathrm{C}$ [11-14]. Fig.1, shows the schematic diagram sequence of steps involved in squeeze casting, A performance was put into the mold and preheated with the mold to the solidus temperature of $6061 \mathrm{Al}$ alloy, which is $580^{\circ} \mathrm{C}$. Molten $\mathrm{Al}$ alloy heated at $700^{\circ} \mathrm{C}$ was then poured into the mold, followed by the push action of the preheated ram, under the control of the hydraulic press were adopted in this work.

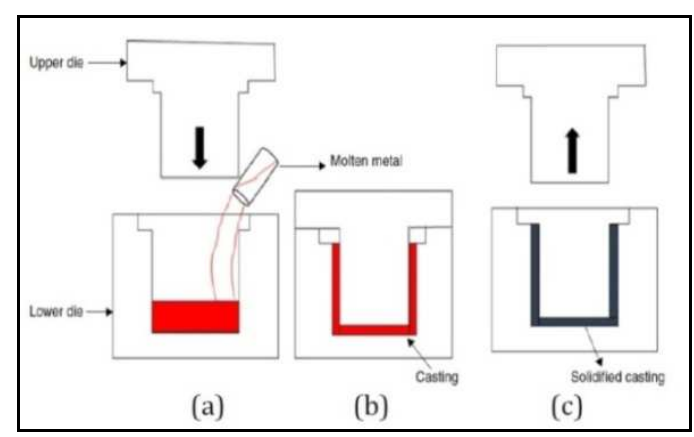

Figure 1: Schematic Diagram Illustrating the Sequence of Steps Involved in Squeeze Casting

(a) Molten metal poured into the pre-heated die, (b) application of squeeze pressure and (c) solidified casting.

In squeeze casting of the composites, a pressure of $100 \mathrm{MPa}$ was applied, until the ram could no longer advance, which meant that, the penetration of the liquid metal into the preform was completed. After casting, the composite was cooled.

\section{CHARACTERIZATIONS}

Casting composites test specimens were prepared by ASTM standard, for various tests. Microstructure 
characterization was implemented on the prepared composite specimen, to investigate the distribution of Al6061 and $\mathrm{SiC}$ particles. Rule mixture and Archimedes principal were used, to calculate the theoretical and experimental density of the prepared composite specimen. Fig 2 and 3, shows the tested hardness and impact of the test specimens, Rockwell hardness tester was used to measure the hardness and the Izod impact test was used to find the effect of SiCp on the matrix alloy.

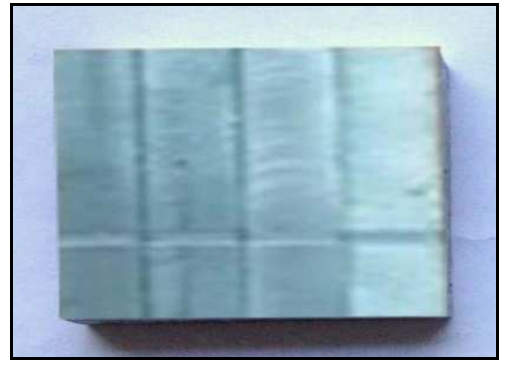

Figure 2: Hardness Test Specime

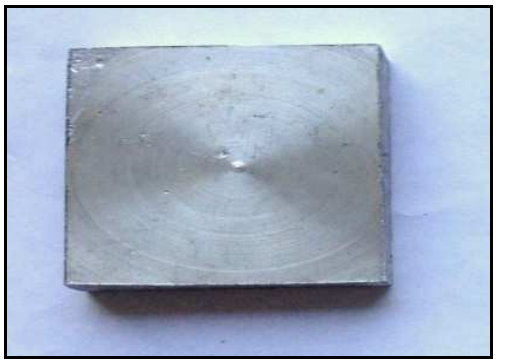

Figure 3: Izod Impact Test Specimen

\section{RESULTS AND DISCUSSIONS}

\section{Microstructure}

Figure 4 shows the optical micrograph of 20 vol. \% of SiCp reinforced aluminium composite. From the Figure 4(a), it was evident that, SiCp was uniformly distributed in the aluminium alloy. Figure 4 (b) revealed that, there was a particle clustering in some places, but there was a strong interfacial bonding between the $\mathrm{SiC}$ particles and aluminium alloy, in this optical micrographs pictures, it shows clearly that, high volume fraction of SiCp are uniformly distributed, through using Squeeze casting technique.

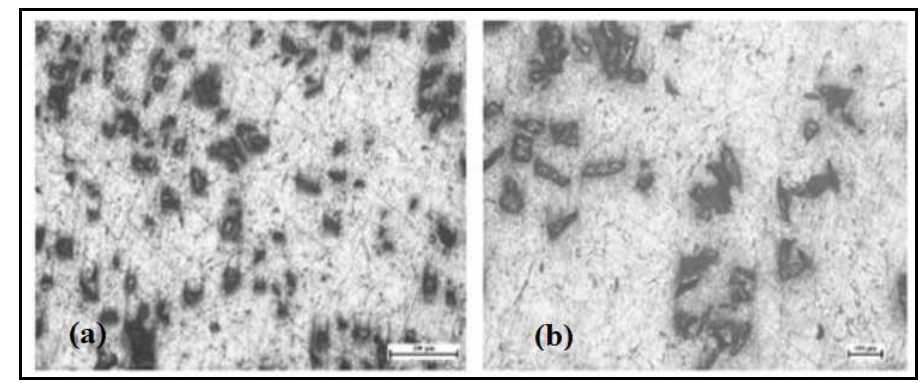

Figure 4: Optical Micrographs of MMC with 20 wt. \% of SiC [50X, 100X]

\section{Density}

Figure 5 shows that, variation in the density of the different $\mathrm{SiCp}$ volume percentage in composites, Densities of the $\mathrm{SiCp}$ and Matrix alloy is $3.2 \mathrm{~g} / \mathrm{cm}^{3}$ and $2.7 \mathrm{~g} / \mathrm{cm}^{3}$, separately. Results shows that, increasing the volume fraction of $\mathrm{SiCp}$ reinforcement and its density values also increased, and the theoretical density of composites was higher than experimental density in the results, as the density of $\mathrm{SiCp}$ was higher than matrix material. 


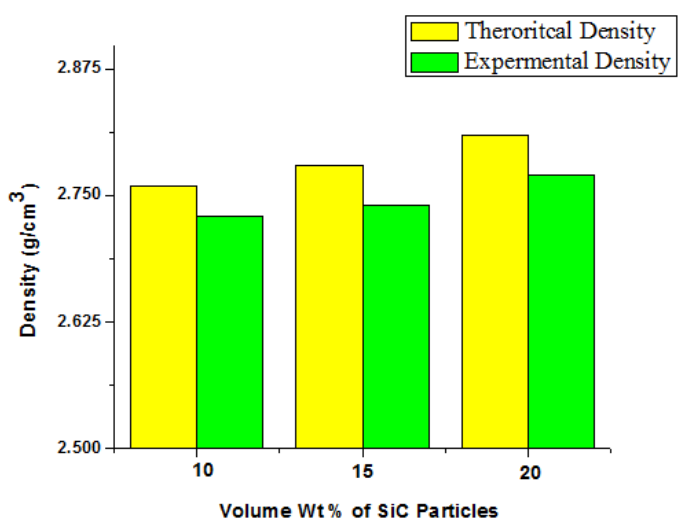

Figure 5: Variation of Density with Volume \% of SiC Particles

\section{Hardness}

Figure 6, shows the variation in hardness of composites with volume \% of $\mathrm{SiC}$ particles. The addition of hard $\mathrm{SiC}$ particles into the soft Al6061 alloy, improved the hardness of composites. The hardness of composites is increased more or less linearly with the volume fraction of reinforcements, in the $\mathrm{Al}$ alloy. This effect could be attributed to the presence of hard $\mathrm{SiC}$ particles, which increases the load-bearing capacity of the material and also, restrict the matrix deformation by constraining dislocation movement.

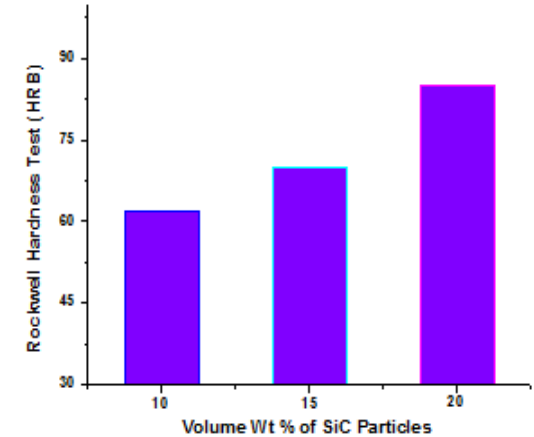

Figure 6: Variation of Hardness with Volume \% of SiC Particles

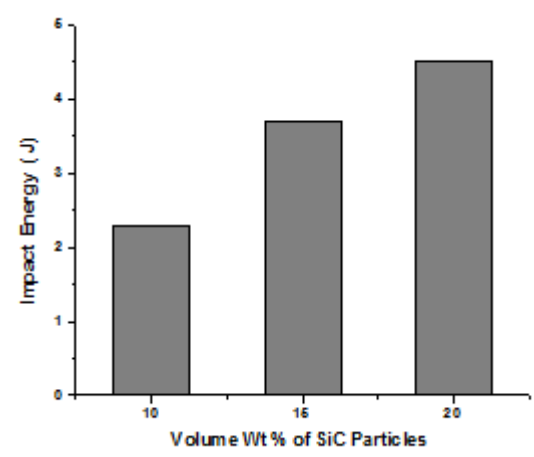

Figure 7: Variation of Impact Energy with Volume \% of SiC Particles

\section{Impact Energy}

The variation in impact energy of composites with volume \% of SiC particles, is presented in Figure7. The impact energy of composites increased linearly, with the volume \% of SiC particles in the Al alloy. This was due to the presence of hard SiC particles, in the matrix alloy.

\section{CONCLUSIONS}

- The Al 6061 -SiC composites were synthesized successfully, using squeeze casting process with varying SiC wt \% $(10 \%, 15 \%$, and $20 \%)$ of reinforcement and the microstructure, mechanical properties are evaluated. From the experimental study, it reveals the following conclusions:

- The Fabrication of aluminum base composites using squeeze casting method, results in a homogenous dispersion 
of the reinforcement particles in the metal matrix. The matrix is almost pore free, showing complete infiltration of the aluminium melt into the $\mathrm{SiC}$ perform.

- Microstructures reveal a uniform distribution of SiC particles in the matrix alloy of $\mathrm{Al} 6061$, with good wett ability and bond between the matrix and reinforcement, which causes high retention percent of $\mathrm{SiC}$ particles in the matrix alloy, and increases the hardness of alloy.

- The values of density in composites are increased, by increasing the volume fraction of reinforcements, but experimental density was lower than theoretical density.

- The hardness and impact energy of composites increased linearly with the volume fraction of reinforcements, in the $\mathrm{Al}$ alloy.

- The mechanical strength of Al6061-20 vol \% SiC composite is superior to those of the 10 and $15 \mathrm{wt} \% \mathrm{Al} 6061$ matrix composite materials.

\section{REFERENCES}

1. Sahin Y, Aclar M (2003) Production and properties of SiCp-reinforced aluminium alloy composites. Compos Part A-Appl S 34: 709-718.

2. Kumar GBV, Rao CSP, Selvaraj N, Bhagyashekar MS (2010) Studies on Al6061-SiC and Al7075- $\mathrm{Al}_{2} \mathrm{O}_{3}$ Metal Matrix Composites. Journal of Minerals and Materials Characterization and Engineering 9: 43-55.

3. Miracle DB, Donaldson SL (2002) ASM Handbook Volume 21: Composites

4. Huda D, El Baradie MA, Hashmi MSJ, Metal matrix Composites: Manufacturing aspects. J mater process Technol 1993:37:513.

5. Hwu, B., Lin, S. and Jahn, M. "Effect of process parameters on the properties of squeeze cast SiCp- 6061 Al metal matrix composite", Materials Science and Engineering, A207, p 135 (1996).

6. Hwu, B., Lin, S. and Jahn, M. "The interfacial compounds and SEM fractography of squeeze cast SiCp /6061 Al composites", Materials Science and Engineering, A206, p 110 (1996).

7. Kok M (2005) Production and mechanical properties of Al2O3 particle-reinforced 2024 aluminium alloy composites. J Mater Process Tech 161: 381-387.

8. A. Chennakesava Reddy, Studies on Loading, Cracking and Clustering of Particulates on the Strength and Stiffness of 7020/SiCp Metal Matrix Composites, International Journal of Metallurgical \& Materials Science and Engineering (IJMMSE), Volume 5, Issue 1, January - February 2015, pp. 53-66

9. SedatOzden, RecepEkici, Fehmi Nair, Investigation of impact behaviour of aluminium based SiC particle reinforced metalmatrix composites, Composites: Part A 38 (2007) 484.

10. Zhang Peng, Li Fuguo, Effects of Particle Clustering on the Flow Behavior of SiC Particle Reinforced Al Metal Matrix Composites, Rare Metal Materials and Engineering 39 (2010) 1525.

11. M. M. Siva et al., Effect of Microstructure and Hardness Properties of Al2011 based Composites for Titanium Di Boride using Stir Casting Method, International Journal of Mechanical and Production Engineering Research and Development (IJMPERD), Volume 7, Issue 2, March - April 2017, pp. 187-200 
12. T.S. Srivatsan, Meslet Al-Hajri, V.K. Vasudevan, Cyclic plastic strain response and fracture behavior of 2009 aluminum alloy metal-matrix composite, International Journal of Fatigue27 (2005) 357.

13. S. M. Seyedreihani, Processing of Squeeze cast Al 6061-30Vol\% SiC Composites and their characterization, materials and deisgn 27 (2006) 216-222.

14. Hemanth RD., M. Senthil kumar, Ajith gopinath \& Natrayan. L, Evaluation of mechanical properties of E-Glass and Coconut fiber reinforced with polyester and Epoxy resin matrices, International Journal of Mechanical and Production Engineering Research and Development (IJMPERD), ISSN (P): 2249-6890; ISSN (E): 2249-8001, Vol. 7, Issue 5, Oct 2017, 13-20.

15. G.B. Veeresh Kumar, C.S.P. Rao, N. Selvaraj. Studies on mechanical and dry sliding wear of Al6061-SiC composites. International Journal of Scientific \&Engineering Research. (2012) 1185-1191.

16. S. Ray, "Review: Synthesis of cast metal matrix particulate composites", Journal of Material Science. 28 (1993) $5397-5413$. 